\title{
Lisbona Guillén, Miguel y Justus Fenner (coord.) (2010), La Revolución mexicana en Chiapas, un siglo después, México: PROIMMSE-IIA-UNAM y Gobierno del Estado de Chiapas, pp. 500, ISBN 978-607-02-1400-4.
}

$\mathrm{D}$ ice Jan Rus en los comentarios finales de este libro, por varias razones excepcional, que el evento más importante del siglo XX chiapaneco no es la Revolución mexicana sino el auge y caída de las fincas; un fenómeno objeto de estudios pioneros como los de Sonia Toledo Tello y más recientemente Gabriel Ascensio Franco, y que de muchas maneras como Rus señala acerca la historia a la antropología, abriendo nuevos horizontes interpretativos y preguntas que seguramente motivarán nuevas investigaciones.

Este libro coordinado por Justus Fenner y Miguel Lisbona es oportuno no sólo por salir a la luz en pleno año de centenarios y bicentenarios, sino por su crítica originalidad y su demanda explícita de más investigaciones planteada en casi todos los capítulos. Esto lo hace un valioso instrumento de trabajo, preñado de interrogantes y respuestas que rompen tabúes, estereotipos y verdades preconcebidas e ideologizadas, sobre las varias versiones de la Revolución mexicana en Chiapas. Es un volumen resultado de extensos trabajos etnográficos y de archivo, escrito por investigadores para que lo lean otros investigadores, pero que también debieran conocerlo los profesores de historia de las escuelas secundarias, vocacionales y de las universidades locales y foráneas, semillero de investigadores con ganas de bucear en los archivos y recoger el vigoroso testimonio de los que fueron protagonistas, o son memoriosos depositarios de la tradición oral sobre las revoluciones en Chiapas.

A golpe de vista, lo obvio, pero que vale la pena enfatizar, es la diversa procedencia de los autores, lo que permite un saludable horizonte internacional de discusión, y el contraste de fuentes y miradas amplía las posibilidades de interpretación de temas petrificados por la historiografía oficial, o las creencias e invenciones populares carentes de respaldo fáctico. En la sección introductoria, los coordinadores del volumen revisan las posiciones oficiales, revisionistas y posrevisionistas sobre la Revolución mexicana en Chiapas y nos invitan a tomar distancia de lo políticamente correcto y la crítica vacía de contenidos.

En su contribución, Carlos Martínez Assad problematiza el conceptoúnico de Revolución mexicana para los estados del sureste, y muestra la doble tensión entre formas alternativas de ver al sur desde el centro y desde el norte, y a la inversa: ver desde el sur al centro y al norte, así como la manera en que las distancias, las dificultades en las vías de comunicación, acentúan la convergencia de conservadurismos y estereotipos que retratan la pasividad de los trabajadores rurales o lo reaccionario de las oligarquías regionales. Se cuestiona si la mexicana fue una revolución política (Arnoldo 
Córdova), que movilizó grandes contingentes humanos, y tanto en el artículo de Martínez Assad como a lo largo de todo el libro se ofrece un retrato sólido de las dinámicas del rabasismo, el maderismo, el carrancismo, y el mapachismo. Se abordan las peculiaridades de la modernización porfirista, los cambios en el contexto de la nueva definición fronteriza con Guatemala, las relaciones entre Iglesia y Estado, la abolición de la servidumbre debido a deudas planteada por la retórica del trabajo libre contratado entre mozos y patronos, que como sabemos no implicó la eliminación de la compulsión forzada al trabajo, sino por el contrario el rabasismo ilustrado estuvo convencido de que esa era la mejor manera de hacer avanzar la civilización y el progreso en Chiapas.

Otro aspecto a destacar es el faccionalismo y lo equívoco que puede resultar aplicar etiquetas homogenizantes o demasiado planas para definir ideológicamente a los contendientes, sus estrategias, sus alianzas, la percepción de sus rivales, y la manera como ellos mismos se definen y posicionan. Así un gobierno revolucionario como el de Obregón apoya a un mapachista como Tiburcio Fernández para gobernador, quien a su vez lidereó tropas autoasumidas villistas y opuestas a Carranza.

Miguel Lisbona, en "Del mito político al contra-mito historiográfico", plantea la pertinencia de los estudios regionales y la necesidad de definir qué tipo de revolución hubo en Chiapas, ofreciendo una valiosa recensión de los debates entre revisionistas, como Thomas Benjamin y Alan Knight, y posrevisionistas, cercanos al poscolonialismo estadounidense, como Florence Mallon, ejemplo del "coctel Derrida-Foucault servido a la Gramsci", que critica Mauricio Tenorio citado por Lisbona, quien llama a examinar las diversas estrategias de modernidad, legitimidad y modernización, y a revisar la vigencia de dicotomía tradición-modernidad para juzgar la historia de Chiapas, criticando la postura que asume que en Chiapas no ocurrió nada, y si ocurrió algo fue lo peor de la Revolución: el arribo del Estado nacional corporativo. Dice Lisbona para finalizar que no estaría mal un ejercicio de humildad hermenéutica que ayude a poner en su justo término un período histórico que como la Revolución mexicana está demasiado cargado de visiones de futuro.

Justus, por su parte, insiste en la falta de investigaciones y en la necesidad de tener presente el Chiapas mexicano y el Chiapas centroamericano. Llama a desideologizar los enfoques y la creencia de que las compañías deslindadoras tuvieron mucho que ver en el despojo de tierras comunales y en el crecimiento del latifundio. Utilizando las mismas fuentes que han sido citadas para argumentar en torno al crecimiento de latifundios a partir de los deslindes, un mito políticamente conveniente para finqueros, políticos y funcionarios revolucionarios, astutamente utilizado para esquivar su propia responsabilidad histórica por la miseria en el campo chiapaneco; Fenner dice que el desafío es escribir la historia agraria chiapaneca sin la carga ideológica que la Revolución mexicana nos dejó y reitera su invitación a batallar por más gente y más recursos para la investigación y el rescate de archivos.

En un capítulo que por su acuciosidad y abundancia de fuentes podría más bien convertirse en un libro, Rocío Ortiz Herrera reconstruye la historia de la formación territorial, agraria y social de Chiapa de Corzo, una de las ciudades más pobladas y antiguas de Chiapas cuyo lugar eminente en la historia estatal y regional tiende a olvidarse. Por su parte, Aaron Bobrow-Strain analiza las dinámicas de relación entre terratenientes y organizaciones campesinas en Chilón, las disputas indígenas inter e intracomunitarias, la violencia, el soborno, los rezagos, el papel de los finqueros como mediadores entre el Estado y los campesinos, y la forma como esta mediación provocó en varios casos la colisión entra la territorialidad indígena y la territorialidad finquera. Aborda también el desempeño de otros mediadores como los maestros federales, los caciques indígenas, los comités agrarios y funcionarios federales, que participaron de la constitución de un Estado 
benevolente que se supone reemplazaría el paternalismo de los finqueros.

El fluido relato de María del Carmen Legorreta describe la manera en que se formaron Las Cañadas, municipiode Ocosingo, en la Selva Lacandona, la relación entre mozos y patronos y el papel de los acasillados en la colonización de las áreas adyacentes a las fincas. Con base en entrevistas y fuentes documentales, Legorreta hace una rápida y amena reconstrucción de las relaciones entre Iglesia, hacendados y peones acasillados, y explica la confluencia de los diversos conservadurismos y acciones revolucionarias que dan fe del arraigo de las relaciones de servidumbre, destacando el caso de los finqueros que anduvieron en campaña militar acompañados de sus peones y sirvientes. Sin ser derrotados militarmente, los finqueros de Ocosingo lograron mantener el control sobre los indígenas, dice Legorreta y se pregunta hasta qué punto esa pasividad, quietud o falta de insurrección popular, tuvo algo que ver con la inexistencia de casos generalizados de despojo de tierras comunales y ejidales en esa región de Chiapas, a diferencia del belicoso sentimiento antiterratenientes que se observó en otras partes del país. Me pregunto hasta qué punto la modernización porfirista en Chiapas y la presencia de intereses extranjeros tomó ventaja de las condiciones de coexistencia entre las comunidades y el latifundio agroexportador, similares a las señaladas por David McCreery para Guatemala. Legorreta revisita figuras señeras como las de Enrique Caballero y Plácido Flores, el tabasqueño organizador, agitador y líder de los acasillados, que encabezóla lucha por una justicia social, paradójicamente desvinculada de la lucha en contra de la desigualdad social. Y es que en la perspectiva de los acasillados era "natural" sentirse inferiores al patrón, y no fueron pocos los que prefirieron permanecer con el patrón en las fincas. Éste, uno de los temas reyes en el estudio de la hegemonía en Mesoamérica, pareciera mostrar como se va de lo servil a lo tutelar para retornar nuevamente a la condición aciudadana o preciudadana vigente hasta nuestros días.
En este punto del análisis de una sociedad marcada por las dinámicas de sus relaciones de servidumbre o sus relaciones serviles, a lo mejor más adelante podría ensayarse una visión más amplia de los repertorios simbólicos que nos permita entender no solo el trabajo forzado, el trabajo no pagado de los mozos, o la administración patrimonial y el usufructo privado del poder público, sino también las ideologías de superioridad e inferioridad que permean todos los sectores desde arriba y desde abajo, y sirven para ordenar, legitimándolo y naturalizándolo, el lugar que corresponde ocupar a cada quien en sociedad, de acuerdo con las reglas no escritas de la blancura, el repudio del igualamiento, el discurso sobre la haraganería, el mito del nativo haragán y la necesidad política de la dictadura; fenómenos todos con una resonancia centroamericana, en donde aparece desdibujada con mayor claridad la vía junker del capitalismo ensayado entre finales del siglo XIX y primera mitad del siglo XX.

Sarah Washbrook aborda la forma en que Emilio Rabasa, "ni caudillo, ni general, ni patriarca", sino ilustrado porfirista, centralizó y racionalizó el cobro de impuestos como el de educación, penalizó la vagancia, impulsó la abolición de la propiedad comunal, y la conversión de la burocracia estatal en una gran empresa comercial que vendía puestos públicos al mayor postor, propiciando la multiplicación de funcionarios corruptos e ineptos, ocupados en justificar el peonaje por deudas, dada la incultura atribuida a los llamados indios, incapaces de entender y cumplir con los términos de la contratación de trabajo libre. Con prejuicios racistas se justificó el trabajo forzado, se negaron derechos políticos a los indígenas, y esta negación se convirtió en un factor legítimo y necesario del progreso económico. Washbrook, señala cómo la privatización del poder estatal, los abusos en el sistema tributario y un "revival" del trabajo forzado, caracterizaron a este porfirismo ilustrado de Rabasa, defensor del peonaje por deudas atacado por "espiritualistas locos" como Francisco León y Flavio Guillén. Aquí tendríamos que pensar hasta qué 
punto el trabajo forzado no fue un "revival colonial", sino un rasgo estructural de lo que como, senalamos antes, en los años setenta se denominaba vía junker del capitalismo.

Ya en la sección final del volumen tenemos una magnífico dosier fotográfico en proceso, organizado por Diana Guillén, que muestra detalles biográficos de su antepasado Flavio Guillén, ex gobernador, maderista, callista, francmasón, que vivió cuatro años en Quetzaltenango y diez en la ciudad de Guatemala. Un trabajo que pareciera más bien una probadita de una obra en proceso. Sarah Osten examina la vida personal y política de Carlos A. Vidal y la fascinante experiencia del Partido Socialista Chiapaneco, así como la triangulación entre Vidal y los gobernadores socialistas de Yucatán, Felipe Carrillo Puerto y Tomás Garrido Canabal de Tabasco, en el marco del ascenso de Plutarco Elías Calles. Se antoja jugar a la heurística histórica y, rompiendo la tradicional dicotomía centroperiferia, que reduce la periferia al rol pasivo de imitador o satélite de lo que sucede en el centro, preguntar iqué habría con el callismo y qué rumbo hubiera tomado la institucionalización de la Revolución en México si tanto Vidal como Carrillo Puerto no hubieran sido asesinados?

En otro tema, fundamental para la construcción de lo regional y lo nacional, Sarelly Martínez Mendoza examina tres periódicos, el Diario de Chiapas, conservador anticarrancista; Chiapas Nuevo, procarrancista; y La Patria Chica, promapachista vocero de Tiburcio Fernández, para mostrarnos a través de esta "pariente pobre de la historia" la sociedad y la vida cotidiana durante el período revolucionario: los conflictos entre Tuxtla y San Cristóbal, la institución de la tradición de informar sin comprometerse, los alegatos en torno a la necesidad política de la dictadura, y la constatación histórica de que en Chiapas los periódicos han dependido durante mucho tiempo del apoyo material proveniente del erario público. El gran tema del aguardiente y su importancia en la historia fiscal del Estado es desarrollado por Juan
Miguel Blasco López, durante un período bastante convulso en el que la economía de plantación y las bandas armadas paralizaban periódicamente la actividad comercial, con la consiguiente pérdida tributaria para el Estado. Sobresalen, en este caso, las componendas mediante las cuales se intentó frenar la caída de los ingresos fiscales resultado de la importación de licores de Oaxaca y de otras partes del país, situación que se quiso remediar mediante los "remates", gracias a los cuales se privatizó la función de cobrar los derechos por fabricación y venta de licores, que permitió a su vez a los rematantes dedicarse ellos mismos a la fabricación y venta de licor, con el consiguiente enriquecimiento personal y familiar, y la elevación de los ingresos de la tesorería estatal. Cierran el libro dos breves comentarios, el de Jan Rus mencionado al principio, y el llamado de Arturo Taracena Arriola a identificar una cronología propia para pensar la Revolución en Chiapas y distinguir la coyuntura de la Revolución de la larga duración de su institucionalización.

Al final se queda uno con un panorama mucho más complejo de la historia moderna chiapaneca y sus relaciones con el centralismo federal, en la que lo anecdótico se convierte en convocatoria para refinar la mirada sobre lo estructural y las particularidades en varios casos precursoras de modernidad relacionadas con el resto del país, como la ley de obreros de 1914, el sufragio femenino o los distintos socialismos de Chiapas y el resto del sureste. Se da por sentada, además, la indiscutible complejidad del hecho revolucionario, no obstante considero que hace falta repensar más desde la antropología y la sociología de la cultura el fenómeno de la dictadura como necesidad política, los mitos y representaciones que la naturalizan y legitiman la condición preciudadana, y el cultivo de lo servil en la intersubjetividad de las personas, no sólo como relación laboral premoderna. En resumen, es un libro lleno de sugerentes discusiones y tareas de investigación sobre la historia de esta Revolución que se ha conmemorado en 2010, y que sigue reclamando la atención de los 
interesados en recuperar la memoria de las elites y las clases populares, hasta ahora dispersa en la voz de personajes de carne y hueso y en los registros oficiales. $\mathrm{Y}$ es que como dicen Lisbona y Fenner, citando a Thomas Benjamin, la institucionalización de la historia de la provincia en México no ha coincidido con su profesionalización.
Jorge Ramón González Ponciano

PROIMMSE-UNAM-IIA 